Chapman University

Chapman University Digital Commons

Psychology Faculty Articles and Research

Psychology

5-9-2019

\title{
Sexuality Through the Lens of Secure Base Attachment Dynamics: Individual Differences in Sexploration
}

Dylan Selterman

University of Maryland

Amanda N. Gesselman

Indiana University

Amy C. Moors

Chapman University, moors@chapman.edu

Follow this and additional works at: https://digitalcommons.chapman.edu/psychology_articles

Part of the Gender and Sexuality Commons, Other Psychology Commons, Personality and $\underline{\text { Social Contexts Commons, Social Psychology Commons, and the Social Psychology and Interaction }}$ Commons

\section{Recommended Citation}

Selterman, D., Gesselman, A. N., \& Moors, A. C. (2019). Sexuality through the lens of secure base dynamics: Individual differences in sexploration. Personality and Individual Differences, 147, 229-236. https://doi.org/10.1016/j.paid.2019.04.049

This Article is brought to you for free and open access by the Psychology at Chapman University Digital Commons. It has been accepted for inclusion in Psychology Faculty Articles and Research by an authorized administrator of Chapman University Digital Commons. For more information, please contactlaughtin@chapman.edu. 


\section{Sexuality Through the Lens of Secure Base Attachment Dynamics: Individual Differences in Sexploration}

\section{Comments}

NOTICE: this is the author's version of a work that was accepted for publication in Personality and Individual Differences. Changes resulting from the publishing process, such as peer review, editing, corrections, structural formatting, and other quality control mechanisms may not be reflected in this document. Changes may have been made to this work since it was submitted for publication. A definitive version was subsequently published in Personality and Individual Differences, volume 147, in date. DOI: 10.1016/j.paid.2019.04.049

The Creative Commons license below applies only to this version of the article.

\section{Creative Commons License}

\section{(c) 1 (1) 90}

This work is licensed under a Creative Commons Attribution-Noncommercial-No Derivative Works 4.0 License.

\section{Copyright}

Elsevier 
Sexuality Through the Lens of Secure Base Attachment Dynamics: Individual Differences in Sexploration

Dylan Selterman, University of Maryland

Amanda N. Gesselman, The Kinsey Institute, Indiana University

Amy C. Moors, Chapman University

This manuscript has been accepted for publication at Personality and Individual Differences.

This copy is a preprint: $10.31234 /$ osf.io/zsg3x

\section{CORRESPONDING AUTHOR:}

Dylan Selterman, Ph.D.

University of Maryland, College Park

1147 Biology/Psychology Building

College Park, MD 20742

Email: Dylan.Selterman@gmail.com 


\begin{abstract}
A key aspect of attachment functioning is the secure base, which empowers people to explore their environments, though some individuals do this more effectively than others. While most researchers have focused on adult attachment dynamics in terms of stress and threat (safe haven), we argue that concerted attention should also focus on relational processes in times of optimal functioning. In this paper, we introduce a new theoretical concept: secure base sexual exploration (or sexploration). We define this as the degree to which individuals are able to effectively explore multifaceted dimensions of sexuality (e.g., behaviors, identity) as a function of secure attachment dynamics. Put another way, we posit that interpersonal attachment security, which is a function of individual and dyadic factors, may meaningfully predict the degree to which individuals are comfortable with sexual exploration. In the first section of our paper, we outline core tenets of attachment theory, followed by an explanation of the secure base construct. We then explain how the secure base construct can be useful in conceptualizing individual differences in sexploration, followed by domain-specific sexual outcomes (e.g., behavior, identity) that may stem from sexploration. Embedded in this discussion is a new approach for researchers to examine these links.
\end{abstract}

Keywords: attachment, secure base, development, exploration, sexuality; thriving 


\section{Sexuality Through the Lens of Secure Base Attachment Dynamics: Individual Differences in Sexploration}

"Sexuality plays a central role in most intimate relationships...it is establishment and maintenance of relatedness that is fundamental, and the mutual exchange of intense pleasure and emotional responsiveness is perhaps the most powerful medium in which emotional connection and intimacy is sought, established, lost and regained." - Mitchell (1988, p. 107).

Despite the considerable importance of sexuality in adult romantic relationships, many researchers investigate romantic attachment dynamics without regard to sexual intimacy. Great strides have been made in understanding relationship maintenance behaviors, such as constructive communication, handling and resolving conflict and creating a safe space for self-expression and self-expansion (Domingue \& Mollen, 2009; Knee, Hadden, Porter, \& Rodriguez, 2013; Pistole, 1989). However, critical theorizing around the role of sexual connection as a meaningful context for the attachment system and secure base script is absent from the literature. Although we understand that attachment bonds and the secure base are developed through emotionally significant interactions (Zeifman \& Hazan, 1997), sexual intimacy has not necessarily been viewed as a significant interaction worth empirically pursuing. In this article, we introduce a new theoretical concept, sexploration, as a trait-like factor that ascertains the degree to which individuals can coconstruct a sex-positive, supportive, and safe environment with their secure base partner(s). Such an environment would allow for cognitive, behavioral, and identity-based exploration in the domain of sexuality, with many positive benefits for both partners and the relationship as a whole.

As illustrated in the opening quote, in this paper we argue that the attachment system-an internal system that serves to spur one to seek connection and support from their attachment figure, 
likely their romantic partner(s)—should be more thoroughly examined in the context of sexuality, with specific attention on the secure base. Here, we extend foundational theorizing about the environments in which the secure base manifests, and how engaging with a secure base in sexual self- and partner-discovery may create positive and beneficial experiences. Below, we first provide an overview of the existing literature on attachment orientations and sexual processes, including gaps in our current understanding. Next, we define the secure base construct and conceptualize it as a useful framework for examining individual differences in sexual processes, and bridge gaps between existing research on secure base behavior with research on sexual processes. Last, we discuss testable predictions for how the secure base dynamics would manifest in sexual processes as well as ways to assess sexploration, with suggestions for future research contributions.

\section{The Attachment System: A Brief Overview}

Attachment theory (Bowlby, 1969/1982, 1973, 1980) was first conceptualized in studies of parent-child bonding. Through observational and experimental studies, Bowlby and others discovered that children systematically vary in their style of bonding and the resulting behavioral manifestations. These different styles of bonding have been most often categorized into three traitlike types that have been observed and documented across cultures (Ainsworth, Blehar, Waters, \& Wall, 1978): anxious attachment, avoidant attachment, and secure attachment. Anxiously attached children commonly showed substantial externalized distress (i.e., fits and tantrums) upon reunions with their primary caregivers after being momentarily separated, which was theorized to result from inconsistent responsiveness by that caregiver to the child's needs. Avoidantly attached children commonly exhibited internalized negative affect (i.e, low enthusiasm or indifference) upon reunions with primary caregivers - a possible consequence of emotional distance from parents or unresponsive caregiving - signaling self-reliance and a belief that one cannot depend on the 
caregiver to satisfy their needs. Both anxious attachment and avoidant attachment indicate a low degree of felt security as a result of their tumultuous relationship with their attachment figure. By contrast, securely attached children were observed to be effectively able to utilize their primary caregivers for emotion regulation, and often had highly responsive and supportive caregivers.

Following this, researchers began to explore attachment theory in the context of adult romantic relationships and personality traits (Hazan \& Shaver, 1987), noting that the bond between adult romantic partners shares essential features of the bond between caregiver and child, and thus likely arise from a co-opted motivational system (e.g., Feeney \& Noller, 1990). Some of these shared features include feeling safe or secure when one's partner is responsive to one's needs, feeling distressed or insecure when one's partner is unavailable or distant, engaging in "baby talk" or other intimacies such as eye-gazing and cuddling, and sharing discoveries with one another. Further research demonstrated that adult romantic partners can be categorized into similar attachment orientations as those for children (e.g., Cassidy, 2000; Hazan \& Shaver, 1987; Shaver, Hazan, \& Bradshaw, 1988). Measures of adult attachment orientations generally operationalize attachment styles as differing along two continuous dimensions: anxiety (i.e., worry about abandonment and insecurity about partner's availability) and avoidance (i.e., discomfort with emotional closeness to a partner; see Cassidy, 2000, for a review). Secure adults score low on both dimensions, being confident in their partner's responsiveness and comfortable with the shared intimacy. Adults high in attachment anxiety experience excessive thoughts of abandonment or betrayal, which lead to dysfunctional and maladaptive attempts to foster closeness and intimacy, and often result in conflict. Adults high in avoidance experience mistrust, but adopt a strategy of emotional distancing and minimization of intimacy, which also results in relational conflict (Simpson, Rholes, \& Phillips, 1996). These traits are relatively stable across time and across relationships, and this stability mimics other trait constructs (Fraley, Vicary, Brumbaugh, \& Roisman, 2011), with room for change over 
time due to changes in relationship dynamics or significant life events (Davila, Burge, \& Hammen, 1997; Davila \& Cobb, 2003; Davila, Karney, \& Bradbury, 1999; Mattingly, McIntyre, \& Selterman, 2018).

Adult attachment orientations have been implicated in a wide variety of romantic and sexual outcomes, well-being, social processes, and attitudes. For instance, in a meta-analysis of 73 studies and 21,602 participants, both anxious and avoidant orientations were negatively associated with romantic relationship quality, including cognitive, emotional, and behavioral contributors (Li \& Chan, 2012). Specifically, anxious attachment was associated with greater frequency of partnered conflict, while avoidant attachment was associated with lower relationship satisfaction, worsened feelings of connectedness, and less social support than for those more securely attached. Avoidant attachment has been linked to less trust (Vicary \& Fraley, 2007) and investment (Pistole, Clark, \& Tubbs, 1995) in romantic partners, as well as with commitment aversion, likely because avoidantly attached individuals perceive closeness and/or intimacy to be risky (Birnie, McClure, Lydon, \& Holmberg, 2009; Brunell, Pilkington, \& Webster, 2007). Attachment orientations guide individual's appraisals of others' behavior, and moral perceptions of right and wrong (Koleva, Selterman, Iyer, Ditto, \& Graham, 2014; Selterman, \& Koleva, 2015).

Adult attachment orientations have been linked to many cognitive and behavioral aspects of sexual behavior (for reviews of this literature, see Birnbaum, 2015; Birnbaum \& Reis, 2018). For instance, motives for engaging in sex have been found to differ across orientations. Across several studies, anxiously attached individuals tended to engage in partnered sexual behavior as a means of assuaging their hyperawareness of felt insecurity, pleasing their partner to avoid abandonment or to reduce conflict (Birnbaum, 2015; Cooper, Pioli, Levitt, Talley, Micheas, \& Collins, 2006; Davis, Shaver, \& Vernon, 2004; Schachner \& Shaver, 2004; Tracy, Shaver, Albino, \& Cooper, 2003). Additionally, highly anxious individuals often report experiencing intruding or distressing thoughts 
during sexual events. These can bring about sexual dysfunction, resulting in even more distress due to these individuals utilizing sex as a method of retaining their partner (Birnbaum 2007, Birnbaum, Reis, Mikulincer, Gillath, \& Orpaz, 2006; Burri, Schweitzer, \& O’Brien, 2014; Stefanou \& McCabe, 2012). As such, anxious attachment has been associated with lowered sexual satisfaction (Birnbaum \& Reis, 2018; Brennan, Wu, \& Loev, 1998). Those more avoidantly attached may often engage in sexual behavior for self-serving goals, such as increasing their feelings of self-worth or to reduce stress (Birnbaum, 2015). These individuals show less relational commitment on average, and desire to avoid intimacy, opting either for masturbation over partnered sex (Bogaert \& Sadava, 2002; Brassard, Shaver, \& Lussier, 2007) or for casual or emotionless sex (Potard, Courtois, Réveillère, Bréchon, \& Courtois, 2017). Avoidant attachment has been associated with significantly lower responsiveness to their partner's relational and sexual needs (Birnbaum, 2015), and often report lower sexual satisfaction than those more securely attached (Tracey, Shaver, Albino, \& Cooper, 2003). In contrast, those with more secure attachment styles often report a preference for sexual behavior within a committed romantic relationship (Brennan \& Shaver, 1995; Stephan \& Bachman, 1999). These individuals report emotional bonding, wanting to express love, and pleasure-seeking as motives for engaging in partnered sexual behavior, with an intent to meet their partner's needs and as well as their own (Tracey, Shaver, Albino, \& Cooper, 2003). As a result, more securely attached people report feeling more positive and less negative emotions during sex than those anxiously or avoidantly attached (Tracey, Shaver, Albino, \& Cooper, 2003). They are more likely to perceive sexual exploration with a partner as positive and enjoyable (Hazan, Zeifman, \& Middleton, 1994), and report greater sexual satisfaction than insecurely attached individuals.

Many of these sexuality-based differences by attachment style can be explained by a representational component of the attachment behavioral system. Psychologically, there are attachment-related mental representations of self and others, which are utilized during sexual 
experiences. Specifically, attachment anxiety is linked with a negative mental model of self, and a positive mental model of others, resulting in lower feelings of self-worth and prioritizations of others over oneself (Mikulincer \& Shaver, 2007). In the sexual domain, this can lead to unsafe or unsatisfying sexual practices (e.g., not using contraception) if anxious individuals are motivated by hyperactive concerns about conflict or abandonment, causing them to value the needs or wants of their partner over their own desires or safety. This 'sexual compliance' may result in coercive or unwanted sex as the anxiously attached person prioritizes their partner's needs over their own (Szielasko, Symons, \& Price, 2013; Tracey, Shaver, Albino, \& Cooper, 2003). Conversely, greater attachment avoidance is linked with a positive mental model of self, and a negative mental model of others, resulting in distancing from any potential emotional or intimate bonding, and a prioritization of oneself over others (Mikulincer \& Shaver, 2007). In the sexual domain, this can manifest in avoidance of sex, lack of responsiveness to their partner's sexual needs and desires, or preferring sex in less intimate contexts (e.g., casual sex), all of which tend to inhibit emotional connection during a sexual experience.

\section{Secure Base Construct: Attachment Theory as a Framework of Exploration}

"Life is best organized as a series of daring ventures from a secure base." - John Bowlby

Although only briefly reviewed above, the existing literature strongly supports a

theoretically-based link between the attachment and sexual systems, as well as a framework for understanding sexual outcomes based on individual differences in attachment styles. However, the scope of this framework has generally been restricted to a conceptualization of and focus on attachment insecurity (e.g., lower or higher levels of attachment anxiety). Although attachment insecurity, including both anxious and avoidant attachment, is certainly a critical component of 
attachment theory and the attachment behavioral system, a key idea postulated by early and contemporary attachment theorists but missing in the majority of contemporary literature is the secure base for exploration (Bowlby, 1988; Feeney, 2004; Feeney \& Collins, 2015). For children, their primary caregiver enacts the role of a secure base. In times of growth and learning, the child engages with their attachment figure, who provides a behavioral base of security in the form of guidance, support, encouragement, and enthusiasm.

In adult relationships, the romantic/sexual partner takes on the role of the attachment figure and acts as the secure base. This dynamic is reciprocal rather than one-sided, meaning that each partner can provide a secure base and utilize other(s) as a secure base, although if there are withindyad differences in attachment security, one partner may be more/less effective at providing security than another. Because secure base utilization is reciprocal and dyadic, it follows that our theoretical construct, sexploration, is also reciprocal and dyadic. Put another way, sexploration happens when individuals act as a secure base for their partner(s) and draw on secure base support from their partner(s). Characteristic secure base behaviors in adult relationships include (a) availability, which entails reliably being present and able to provide support when necessary; (b) noninterference, which entails providing freedom to engage and explore one's environment without constraints; and (c) encouragement, which entails conveying excitement and enthusiasm for one's goal pursuits and challenges (Feeney \& Thrush, 2010). As an example, researchers have created a measure that maps onto these secure base characteristics to assess the extent to which one's spouse helps to build the secure base environment. The Secure Base Characteristics Scale (Feeney \& Thrush, 2010) includes the following representative items: (1) "I am usually willing to take risks and try new things because I know my spouse will be available to help and comfort me if things don't turn out well." (i.e., availability construct); (2) "My spouse is usually very careful not to interfere in my activities when I am trying something new and challenging." (i.e., noninterference construct); and (3) "When I tell my spouse 
about something new that I would like to try, he/she usually encourages me to do it." (i.e., encouragement construct). Thus, the development of a secure base involves receiving cues of one's partner's reliability, responsiveness to one's needs for autonomy, and encouragement from one's partner over time (e.g., encouraging independence and supportive reactions; also see Waters \& Cummings, 2000).

Although limited, research has examined the secure base construct as an aspect of normative attachment-related experiences. That is, in the context of secure attachment, secure base exploration is something that all individuals experience to some extent. However, an important extension of this idea concerns individual differences in the degree to which people are able to effectively utilize a secure base to engage in healthy exploration. Some research suggests that an understanding of secure base exploration manifests as a cognitive script—an ingrained knowledge structure of how one is supposed to interact or behave in scenarios in which the attachment system and resulting secure base is needed-sometimes referred to as the secure base script. This secure base script gives attachment partners a blueprint for navigating such complex scenarios with their partners, and this script manifests in conscious understanding and subconscious processes (Mikulincer, Shaver, SapirLavid, Avihou-Kanza, 2009; Selterman et al., 2012). The secure base script is presumed to follow a specific sequence of events, beginning with an event or idea that prompts a desire for exploration, or an obstacle to exploration, in partner A. In response to this stress or desire, partner A makes a bid for support from partner B, either explicitly or unconsciously. Next, in cases of secure attachment, partner B understands the bid for support and support is offered/given to partner A as needed. Partner A accepts the supportive response, which includes an affective component that feels positive and nurturing, and ultimately effective and helpful. This encourages partner A to renew or further their learning and exploration. Like other attachment-related constructs, the secure base script (i.e., activation of the secure base script as well as the appropriate interactions and behaviors 
when one serves as secure base for another) is likely shaped by early experiences with primary caregivers, and utilized throughout life to facilitate exploration with the surrounding environment.

There have been a few studies examining the secure base in relation to various outcomes. Some have focused on the impact of individual differences in the ability to effectively draw on their attachment figures for a secure base. These studies have found that individuals with more wellformed secure base concepts were better equipped to draw on their attachment figures for support and to achieve resulting higher well-being in the contexts of mental health, parenting sensitivity, and relationship satisfaction (Steele, Waters, Bost, Vaughn, Truitt, Waters, et al., 2014; Waters, Bosmans, Vandevivere, Dujardin, \& Waters, 2015). Additional research has found the ability to sufficiently rely on an attachment figure as a secure base leads to more positive outcomes in terms of personal or professional goal pursuits, physical health, and happiness (see Feeney \& Collins, 2015 for a review). Relatedly, Feeney (2007) collected longitudinal measures of married couples' self-reported goal efficacy and found that aspects of a secure base dynamic (acceptance of dependency) predicted autonomous exploration and goal-directed movement in partners. Taken together, there is evidence that people thrive when they can successfully co-create reciprocal secure bases with their attachment figures. Research has revealed that individuals draw strength from their attachment figures and utilize them for motivational/goal pursuits including career activities, pursuing interests and hobbies, and bettering health and wellness. As such, it follows that sexploration-including cognitive, behavioral, and identity-based exploration — may benefit as a result of secure base utilization.

Concurrently, research has shown that individuals develop other types of relational and sexual scripts that play a role in the ongoing interactions involved with sexual encounters, dating, hooking up, and romantic relationships (e.g., Masters, Casey, Wells, \& Morrison, 2014), although those scripts typically manifest as mental representations that reflect sociocultural norms rather than personality traits. We suggest that in parallel, individuals may develop a sexploration script as a 
function of trait-like and dyadic attachment processes, as something that mirrors the secure base script (Waters \& Waters, 2006). As shown in Figure 1 below, we suggest how sexual exploration with a secure base operates as a scripted process that includes patterns of support and responsiveness which are conceptually similar to the types of support/responsiveness found elsewhere in the attachment literature.

Though this sexploration script has yet to be investigated empirically, there is anecdotal evidence that people form mental representations of pleasurable sex in the context of emotional availability, responsiveness, intimacy, and support. Examples can be found in unstructured interviews with people about their sexual experiences. For example, in Our Bodies, Ourselves (Boston Women's Health Book Collective, 2011), a participant named Madigan says, "I cannot be sexually or emotionally intimate with someone I don't feel safe with. Physical touch and emotional honesty are two major parts of expressing intimacy with anyone I care about (romantic or otherwise)." Another woman describes communicating about sex with her partner thusly: "Negotiating how and when it is okay for me to relinquish control over my physical movements - for example, when it's sexy to have my girlfriend restrain me and when it makes me feel slightly panicky — has been a complicated process. I feel bad that I can't give my girlfriend clearer cues about what feels good when, particularly since she tends to retreat pretty quickly when I say, 'That didn't feel good this time,' to, 'Well, then I'll stop doing it altogether.' That either-or response comes from (I think) not wanting to do something that I don't like, and not wanting rejection, but there are times when I want a little pain, want a little domination, and I feel bad that I can't give her a clearer sense of when and in what circumstances certain activities feel good and when they don't." It is notable that even as individuals describe challenges to sexual satisfaction, they do so in the context of dyadic secure base support, with a desire for openness, honesty, and relational comfort, in a way that mirrors the traditional secure base script described earlier. 


\section{Secure Base Script and Sexuality: How Could Sexploration Manifest in Different Domains?}

Given that the secure base function of attachment serves primarily to facilitate development and exploration, it follows that individuals would engage with their secure base as a prerequisite of sexploration, with positive outcomes for the relationship. Sexuality is a multifaceted construct, including cognitive appraisals, desires, and behaviors (c.f. Penke \& Asendorpf, 2008). As such, sexploration could function in different domains at the individual- and dyadic-level. In this section, we elaborate further on links in the current relationships literature that detail the impact of a secure attachment environment and accompanied secure base exchanges on sexploration in (1) cognitive, (2) behavioral, and (3) identity-based domains.

Cognitive exploration. One aspect that is central to sexuality is cognition--the ways in which people process and attend to information, including appraisals, desires, and motivations. Ample research has consistently shown that attachment orientations correlate with affective variables in the sexual domain. For instance, people with more avoidant attachment tend to experience more negative and less positive emotions associated with sex (sometimes referred to as erotophobic attitudes), compared to individuals with a more secure attachment (Birnbaum, Reis, Mikulincer, Gillath, \& Orpaz, 2006; Tracy et al., 2003). Attachment anxiety, by contrast, correlates with both positive and negative affective states, including pleasure and also disappointment (Birnbaum, 2007; Birnbaum et al., 2006). These findings suggest that the ability to engage with the secure base may impact affective responses to sex. Avoidant individuals tend to resist emotional reliance on partners, and thus are unlikely to try and activate a secure base environment. They may feel negative affect with the sexual contact because they cannot effectively utilize sexual partners as a secure base; they are concerned about perceived threats with increasing intimacy, and engage in minimization strategies that dampen pleasurable feelings. Conversely, more anxiously attached individuals seek deep intimacy with others, so may be over-relying on the environment and 
attachment figure. This may create a struggle to effectively utilize partners as a sexual secure base, but despite this, their desire for closeness may produce positive affect and pro-relationship behaviors, explaining the experience of both positive and negative emotional states (Birnbaum et al., 2006). Thus, the psychological disconnection between intimacy with the attachment figure and secure base may be the underlying mechanism explaining these associations between affect and sex.

Sexual fantasies are another context in which the secure base script is likely to be called upon. Sexual fantasies are a common feature of human sexuality. In a recent study-the largest study of sexual fantasies to date— $-97 \%$ of Americans reported having sexual fantasies, with most reporting frequent fantasizing (Lehmiller, 2018). The reported types and topics of fantasies ran the gamut, from group sex (the most popular reported fantasy), to sadomasochism, to cuckold fantasies and beyond. It seems that sexual fantasizing allows for sexual exploration without consequence, and is limited in topic only by the bounds of imagination. However, studies have shown that fantasies are affected by attachment dynamics. For instance, Birnbaum (2012) demonstrated that sexual fantasies differ based on the fantasizer's level of felt security. In this study, participants imagined either a relationship in which they could easily feel close to their partner, versus one in which it was difficult to feel close to their partner, and then reported their sexual fantasies. In comparison to participants who visualized a close relationship, participants who visualized the more insecure relationship reported fantasies in which they themselves were portrayed as intensely sexually desirable. However, they were also portrayed as sexually aggressive with little expressed affection or emotional connection with their partner, perhaps indicating no engagement with the secure base. In a similar study, Birnbaum (2012) found that participants who were primed with thoughts of an insecure relationship more often reported fantasies with themes of distancing from the partner, and hostility directed toward the partner, again suggesting a disconnect with the secure base. The author interpreted these findings as possible evidence of a self-protective strategy, removing any possibility 
of rejection to protect their own self-esteem and self-concept. Taken together, these studies demonstrate that cognitive sexual exploration can be limited and impacted by the types of partners and experiences that one encounters, and can generate positive or negative feelings about the self and others based on felt security — and likely the ability to draw on their secure base—in their relationships.

Based on prior research, it seems as though a reliable secure base would have a positive influence on the emotional impact of sex, as well as the content of one's sexual fantasies, although perhaps non-consciously. As the secure base provides feelings of security, and support and enthusiasm for sexual exploration, it is likely that both partners would experience greater positive affect and less negative affect following a sexual event. Additionally, themes emerging in partners' sexual fantasies are likely to positively represent both the self and others present in the fantasy world, with an affective connection between the two (or more) partners. This would allow for 'testing the waters' of new sexual behaviors or contexts (e.g., BDSM, group sex, sex with other genders) to better understand one's sexual desires, needs, and identities. This may lead to more sexual communication and greater pleasure during sexual events. Longitudinally, these positive outcomes may lead to better sexual well-being and more satisfying relationships, which in turn are often linked with greater overall mental and physical well-being (Uchino, Cacioppo, \& KiecoltGlaser, 1996).

Behavioral exploration. Another central aspect to sexuality are people's behaviors, including solo, paired, or group sexual behaviors. In terms of self-exploration, masturbation is a common practice, albeit more so in men than in women (Hyde \& Jaffee, 2000). However, research has shown that the "exploration" component is lacking. In a study of 883 undergraduate students, only $29 \%$ of women and $27 \%$ of men were able to accurately identify the clitoris on a diagram of the 
vulva (Wade, Kremer, \& Brown, 2005). Clitoral stimulation has been pinpointed as a near-essential component of female orgasm (Wade, Kremer, \& Brown, 2005), but this lack of knowledge and resulting lack of guidance provided to one's partner may is likely due to the shame and stigma that has surrounded masturbation throughout history. In fact, the former American Surgeon General, Jocelyn Elders, was forced to resign following the negative public reaction to her claim that masturbation should be discussed as part of the typical curriculum in school sexual education programs (Hogarth \& Ingham, 2009; Roberts, 1994). Nevertheless, some studies have acknowledged the possibility that masturbation may be beneficial to self-understanding, resulting in greater social competence, self-development, and well-being — all of which provide some of the skills needed for engaging in intimate relationships and for co-creating a secure base environment (Haffner, 1998; Horne \& Zimmer-Gembeck, 2005; Moore \& Rosenthal, 1993). While we know of no research to date on masturbation, masturbatory pleasure, or self-exploration in association with attachment orientations, beyond the finding that highly avoidant individuals may prefer masturbation over partnered sex (Bogaert \& Sadava, 2002; Brassard, Shaver, \& Lussier, 2007). In the context of sexploration, individuals may utilize a secure base for support and encouragement in bodily exploration, with the intent of finding methods (e.g., movements, amount of applied pressure) or locations (e.g., the clitoris) where one can experience consistent pleasure. This exploration would be likely to positively influence future sexual events, thereby increasing sexual satisfaction and in turn, increasing relationship satisfaction and felt partner connection (Yeh, Lorenz, Wickrama, Conger, \& Elder, 2006).

In the context of partnered bodily exploration, there are documented links between attachment orientation and kinky sexual behaviors, including bondage-discipline, dominancesubmission, sadism/masochism (BDSM). Some studies have investigated BDSM in conjunction with personality traits, including attachment orientations, and found that scores on attachment 
variables are generally similar when comparing BDSM practitioners and non-practitioners (Wismeijer \& van Assen, 2013). However, BDSM practitioners were found to score lower in attachment avoidance than non-practitioners, indicating greater comfort with intimate connection than non-practitioners (Wismeijer \& van Assen, 2013). A hallmark of BDSM/kink is the caring, honest, and accepting discussion of what specific behaviors are enjoyable, even if they are physically painful, and these aspects mirror what scientists have documented in secure attachment patterns. Thus, although we cannot speculate on directionality of these findings, BDSM practitioners may be more effectively engaging with their secure base to more comfortably and positively experience pleasurable erotic activities as their BDSM practicing partner can be counted on to be available, to not interfere or reject their sexual desires as they have been discussed and accepted beforehand, and to provide support and encouragement.

Last, attachment orientation may be related to exploring different forms of sexual partnerships. People who engage in consensually non-monogamous relationships-mutual agreements to engage in romantic and/or sexual relationships with multiple concurrent partnersare stereotyped as insecure, unhappy, and sexually dissatisfied (Moors, Matsick, Ziegler, Rubin, \& Conley, 2013; Rodrigues, Fasoli, Huic, \& Lopes, 2018). Yet, a growing body of research on relationship quality among people engaged in consensual non-monogamy has not found evidence to support these stereotypes (e.g., Conley, Matsick, Moors, \& Ziegler, 2017; Moors, Matsick, \& Schechinger, 2017; Rubel \& Bogaert, 2015). In fact, few differences in relationship functioning and quality emerge between people in consensually non-monogamous and monogamous relationships (e.g., Conley et al., 2017). In some cases, people in consensually non-monogamous relationships report higher quality (e.g., low jealousy) and unique benefits, such as personal growth and diversified need fulfillment (Moors et al., 2017). 
From an attachment perspective, perhaps some are better equipped to navigate multiple emotional and sexual partners than others. For instance, people with insecure attachments (i.e., avoidance or anxiety) tend to experience discomfort with closeness or worry about a partner's availability may not have orientations that are best suited for sexploration with multiple partners (e.g., Cassidy, 2000). Instead, a secure base-one from which an individual could explore romantic and/or sexual connections with outside of monogamy—may be a hallmark of consensually nonmonogamous relationships. Although understanding consensually non-monogamous relationships is a relatively small body of research, there is some support for the notion that sexploration may be at play. In one study, Moors and colleagues (2015) examined how attachment orientations were linked with three facets of consensual multi-partnered exploration: attitudes, desire, and behavior. Among people who had never engaged in consensual non-monogamy, highly avoidant individuals endorsed more positive attitudes (e.g., "If people want to be in an open/consensually non-monogamous relationship, they have every right to do so") and greater willingness to engage in consensual nonmonogamy (e.g., "you and your partner take on a third partner to join you in your relationship on equal terms"). Highly anxious individuals tended to hold negative attitudes toward consensual nonmonogamy (anxiety was unrelated to willingness). However, when actual behavior was examined, low avoidance was linked with current engagement in a consensually non-monogamous relationship, relative to engagement in a monogamous relationship (Moors et al., 2015). In other words, avoidant individuals desire consensual non-monogamy in the abstract, but ultimately, people currently in consensually non-monogamous relationships exhibit aspects of attachment security. These findings suggest that one's ability to co-create a secure base environment with one's primary partner provides the foundation for exploring consensual non-monogamy and receiving the benefits that multipartner dynamics can provide. Future work in this area can examine underlying communication 
mechanisms (Moors et al., 2017; Ritchie \& Barker, 2006) that facilitate sexploration among people who are interest in trying out or currently engaged in consensually non-monogamous relationships.

Identity-based exploration. The ways in which people conceptualize their romantic and/or sexual attraction to others--identity--is also a important component to sexuality. There are many types of sexual identities, including identities relevant for understanding sexual orientation, gender, sexual preferences, traits, and many more. All may be linked to some extent with a sexual self-concept, that is, a working mental representation of oneself in the sexual domain. Perhaps as a result of exploring one's sexual self-concept, attachment security has been linked with greater selfacceptance and positive attitudes toward one's own sexual identity, including within gay, lesbian, and bisexual populations (e.g., Mohr \& Fassinger, 2003). Secure attachment, and associated selfacceptance, also facilitates being open or "out" for non-heterosexuals and disclosure of sexual orientation to others, which has been linked to better mental well-being overall (Mohr \& Fassinger, 2003). Though no research to date has examined this, individuals who can more effectively draw on their secure base during identity exploration and receive the resulting support may be more likely to experience these positive outcomes, whereas those less effective may be less likely to disclose their identities or accept their sexual identities, leading to negative well-being and mental health.

Another way in which a secure base could be related to identity-based exploration is through partner exploration. Through fantasizing or actual engagement in sex, people may discover what kinds of people they are attracted to, and what kinds of sexual partners they prefer. Most studies on partner preferences include prompts about general characteristics, such as sexiness or intelligence (e.g., Eastwick \& Finkel, 2008), but how those preferences develop is less well studied, and virtually no research exists on how those preferences may be shaped by sexual experiences. For example, research on sexual fluidity (Diamond, 2008) and erotic plasticity (Baumeister, 2000) shows that people's sexual preferences may change in middle adulthood as a function of romantic experiences, 
and this can lead to changes in sexual identity. To what extent this sexual identity development in adulthood is facilitated by secure base exploration remains a topic to be studied, however, those effectively utilizing a secure base may be better able to develop clearer preferences for sexual partners, perhaps in terms of their desired physical characteristics (e.g., body type), or personality characteristics (e.g., generosity).

In sum, the attachment literature has conceptualized effective support in terms of felt security (Mikulincer \& Shaver, 2007), meaning that it is the feeling that one has a secure base that predicts confidence in exploration, and in this specific case, sexploration. In theory, to the extent that an individual feels securely attached to their partner(s), and believes that they can rely on their secure base to be available, to not interfere, and to provide encouragement and support, that individual can engage in healthy sexploration. In such a model, sexploration serves as the predictor for an array of sexual outcomes (cognitive, behavioral, identity-based), which we have articulated above.

\section{Moving Forward and Concluding Thoughts}

The goal of the present paper is to shine a spotlight on the functionality of a secure base in the context of sexuality. We introduce a new theoretically-grounded concept, sexploration, which captures the degree to which a person co-constructs a sex-positive, supportive, and safe environment with their partner(s). As such, we propose that this sex-positive secure base could allow for people to (s)explore the multifaceted dimensions of sexuality, including cognitive, behavioral, and identity-based avenues. While the majority of adult attachment research that has focused on secure base has done so in the context of exploration in the natural environment, our contribution extends this theory into the sexual domain — an integral part of intimate adult relationships. In this 
light, sex can be considered psychologically similar to anything else in life that stems from exploration (e.g., sensorimotor development in infancy, social interactions, academic learning).

Individual differences in attachment are often framed within the context of dimensions of insecurity (anxiety and avoidance), which can have the unintended consequence of misperceiving that attachment orientations are traits the predict dysfunction. By contrast, the secure base framework allows researchers to (re)conceptualize attachment-related individual differences in exploration, growth, learning, and development. Theoretically, the concept of sexploration bridges existing work on individual differences in sexual functioning with a developmental perspective on sexual processes. That is, with the study of sexploration, we can learn more about sexual trajectories in romantic pairings, including how couples arrive at sexual outcomes (e.g., satisfaction) based on the amount of support they feel. The developmental approach to adult attachment in general has yielded knowledge showing how individual differences in secure base usage are linked with effective conflict resolution, stress management, and communication over long periods of time (Crowell, Treboux, Gao, Fyffe, Pan, \& Waters, 2002; Treboux, Crowell, \& Waters, 2004), and we suggest that further research on sexploration from a developmental perspective may inform long-term outcomes in the sexual domain. Among other possibilities, it may be the case that partner-specific attachment security matters more in terms of predicting sexual outcomes in marriage compared to general or parent-centered attachment security, or it may be the case that having a deep-seated secure mental representation based on childhood experiences would be a more powerful predictor than current romantic relationship security (Treboux et al., 2004).

This line of research may also inform identity development--that is, how people experience change in their self-concepts and preferences as a function of secure base support. Currently, the literature has abundant research on these variables from a cross-sectional perspective (e.g., Water et al., 2015), but less on how they unfold as part of ongoing relational processes, such as the formation, 
maintenance, or dissolution of attachment bonds. Just as secure base theory offers a new conceptualization on thriving in close relationships (Feeney \& Collins, 2015), our extension of this model into the sexual domain provides a framework to understand sexual thriving. Future research may reveal that the path to sexual thriving is not uniform for all individuals. This has been suggested for research on general well-being as a function of secure base support (Fraley, 2019), and the types of questions that secure base theorists are posing would be useful to sex researchers as well.

In addition to linear associations between individual differences in secure base usage and sexual outcomes, there may be dyadic effects or interactions that future research should consider. We posited above that given the tenets of adult attachment bonds as reciprocal, each partner can draw on secure base support from the other, as well as provide a secure base for the other. Thus, one's own sexual outcomes would depend in part on the degree to which they feel securely attached and to the extent that their partner(s) provide a stable sexual secure base. In addition, perhaps one's own sexual exploration (or satisfaction) is enhanced to the degree that they serve as a sexual secure base for their partner's sexual exploration. If so, this would be consistent with (and conceptually analogous to) the research on sexual communal strength, which is linked with greater sexual and relationship satisfaction for both partners (Muise \& Impett, 2015; Muise, Impett, Kogan, \& Desmarais, 2013). Underlying this dynamic is that idea that people report greater satisfaction when their partners' needs are met, even if the specific behaviors that please their partners sexually are distinct from their own desires. But this dyadic communal strength does not occur when people focus on their partner's needs at the exclusion of their own needs. Put another way, people can desire to please their partners, which is linked with higher satisfaction, but neglecting one's own needs is associated with lower satisfaction (Impett, Muise, \& Harasymchuk, 2018). We suggest that future research investigate whether sexploration dynamics function in a similar way, such that 
individuals' sexual outcomes benefit to the extent that they and their partner both support each other's sexual exploration.

Moreover, there are practical and applied considerations, as prior work shows how secure base usage is linked with positive life outcomes and well-being (Feeney, 2004; Mikulincer, et al., 2009). Perhaps, research on secure base exploration in the sexual domain could inform the development of healthy sexual scripts, providing a framework for affirmative consent, clear sexual communication, and related outcomes. In sum, we encourage scientists incorporate secure base exploration into sexual dynamics, particularly with a focus on helping identify positive exploratory behaviors in the sexual domain. 


\section{References}

Ainsworth, M. D. S. (1982). Attachment: Retrospect and prospect. In C. M. Parkes \& J. Stevenson-Hinde (Eds.), The Place of Attachment in Human Behavior(pp. 3-30). New York, NY: Basic Books.

Ainsworth, M. D. S., Blehar, M. C., Waters, E. \& Wall, S. (1978). Patterns of attachment: A psychological study of the strange situation. Hillsdale, NJ: Erlbaum.

Baumeister, R. F. (2000). Gender differences in erotic plasticity: The female sex drive as socially flexible and responsive. Psychological Bulletin, 126(3), 347-374. https:// doi-org.proxyum.researchport.umd.edu/10.1037/0033-2909.126.3.347

Birnbaum, G. E. (2007). Attachment orientations, sexual functioning, and relationship satisfaction in a community sample of women. Journal of Social and Personal Relationships, 24, 21-35.

Birnbaum, G. E. (2015). On the convergence of sexual urges and emotional bonds: The interplay of the sexual and attachment systems during relationship development. In J. A. Simpson, W. S. Rholes, J. A. Simpson, W. S. Rholes (Eds.), Attachment theory and research: New directions and emerging themes (pp. 170-194). New York, NY, US: Guilford Press.

Birnbaum, G. E., Mizrahi, M., Kaplan, A., Kadosh, D., Kariv, D., Tabib, D., .. Burban, D. (2017). Sex unleashes your tongue: Sexual priming motivates self-disclosure to a new acquaintance and interest in future interactions. Personality and Social Psychology Bulletin, 43(5), 706-715. https://doi-org.proxyum.researchport.umd.edu/10.1177/0146167217695556

Birnbaum, G. E., \& Reis, H. T. (2018). Evolved to be connected: the dynamics of attachment and sex over the course of romantic relationships. Current Opinion in Psychology, 25, 11-15.

Birnbaum, G. E., Reis, H. T., Mikulincer, M., Gillath, O., \& Orpaz, A. (2006). When sex is more than just sex: Attachment orientations, sexual experience, and relationship quality. Journal of Personality and Social Psychology, 91, 929-943.

Birnbaum, G. E., Simpson, J. A., Weisberg, Y. J., Barnea, E., \& Assulin-Simhon, Z. (2012). Is it my overactive imagination? The effects of contextually activated attachment insecurity on sexual fantasies. Journal of Social and Personal Relationships, 29(8), 1131-1152. https://doi-org.proxyum.researchport.umd.edu/10.1177/0265407512452978

Birnie, C., McClure, M. J., Lydon, J. E., \& Holmberg, D. (2009). Attachment avoidance and commitment aversion: A script for relationship failure. Personal Relationships, 16, 79-97.

Bogaert, A. F., \& Sadava, S. (2002). Adult attachment and sexual behavior. Personal Relationships, 9, 191-204.

Boston Women's Health Book Collective. (2011). Our Bodies, Ourselves. New York: Simon \& Schuster.

Bowlby, J. (1969/1982). Attachment and loss: Vol. I. attachment. New York: Basic Books.

Bowlby, J. (1973). Attachment and loss: Vol. II. separation: anxiety and anger. New York:Basic Books. 
Bowlby, J. (1980). Attachment and loss: vol. iii: loss: sadness and depression. New York: Basic Books.

Bowlby, J. (1988). A secure base. New York: Basic Books.

Brassard, A., Shaver, P. R., \& Lussier, Y. (2007). Attachment, sexual experience, and sexual pressure in romantic relationships: A dyadic approach. Personal Relationships, 14, 475-494.

Brennan, K. A., \& Shaver, P. R. (1995). Dimensions of adult attachment, affect regulation, and romantic relationship functioning. Personality and Social Psychology Bulletin, 21, 267-283.

Brennan, K. A., Wu, S., \& Loev, J. (1998). Adult romantic attachment and individual differences in attitudes toward physical contact in the context of adult romantic relationships. In J. A. Simpson \& W. S. Rholes (Eds.), Attachment Theory and Close Relationships (pp. 248-256). New York: Guilford Press.

Brunell, A. B., Pilkington, C. J., \& Webster, G. D. (2007). Perceptions of risk in intimacy in dating couples: Conversation and partner perceptions. Journal of Social and Clinical Psychology, 26, 93-117. doi:10.1521/jscp.2007.26.1.92

Burri, A., Schweitzer, R., \& O’Brien, J. (2014). Correlates of female sexual functioning: Adult attachment and differentiation of self. Journal of Sexual Medicine, 11, 2188-2195.

Cassidy, J. (2000). Adult romantic attachments: A developmental perspective on individual differences. Review of General Psychology, 4(2), 111-131.

Cooper, M. L., Pioli, M., Levitt, A., Talley, A., Micheas, L., \& Collins, N. L. (2006). Attachment styles, sex motives, and sexual behavior: Evidence for gender specific expressions of attachment dynamics. In M. Mikulincer \& G. S. Goodman (Eds.), Dynamics of love: Attachment, caregiving, and sex (pp. 243-274). New York: Guilford Press.

Conley, T. D., Matsick, J., Moors, A. C., \& Ziegler, A. (2017). The Investigation of consensually nonmonogamous relationships: Theories, methods and new directions. Perspectives on Psychological Science, 12(2), 205-232.

Davila, J., Burge, D., \& Hammen, C. (1997). Why does attachment style change? Journal of Personality and Social Psychology, 73(4), 826-838. https://doi-org.proxy-um.researchport.umd.edu/10.1037/0022$\underline{3514.73 .4 .826}$

Davila, J., \& Cobb, R. J. (2003). Predicting change in self-reported and interviewer-assessed adult attachment: Tests of the individual difference and life stress models of attachment change. Personality and Social Psychology Bulletin, 29(7), 859-870. https://doi-org.proxyum.researchport.umd.edu/10.1177/0146167203029007005

Davila, J., Karney, B. R., \& Bradbury, T. N. (1999). Attachment change processes in the early years of marriage. Journal of Personality and Social Psychology, 76(5), 783-802. https://doi.org/10.1037/00223514.76.5.783 
Davis, D., Shaver, P. R., \& Vernon, M. L. (2004). Attachment style and subjective motivations for sex. Personality and Social Psychology Bulletin, 30, 1076-1090.

Diamond, L. (2008). Sexual fluidity: Understanding women's love and desire. Cambridge, MA: Harvard University Press.

Domingue, R., \& Mollen, D. (2009). Attachment and conflict communication in adult romantic relationships. Journal of Social and Personal Relationships, 26(5), 678-696.

Eastwick, P. W., \& Finkel, E. J. (2008). Sex differences in mate preferences revisited: Do people know what they initially desire in a romantic partner? Journal of Personality and Social Psychology, 94(2), 245-264. https://doi-org.proxy-um.researchport.umd.edu/10.1037/0022-3514.94.2.245

Feeney, B. C. (2004). A Secure Base: Responsive Support of Goal Strivings and Exploration in Adult Intimate Relationships. Journal of Personality and Social Psychology,87(5), 631-648. doi:10.1037/00223514.87.5.631

Feeney, B. C. (2007). The dependency paradox in close relationships: Accepting dependence promotes independence. Journal of Personality and Social Psychology, 92, 268-285.

Feeney, B. C., \& Collins, N. L. (2015). A new look at social support: A theoretical perspective on thriving through relationships. Personality and Social Psychology Review, 19(2), 113-147. doi:10.1177/1088868314544222

Feeney, B. C., \& Thrush, R. L. (2010). Relationship influences on exploration in adulthood: the characteristics and function of a secure base. Journal of Personality and Social Psychology, 98, 57-76. doi: $10.1037 / \mathrm{a} 0016961$

Feeney, J. A., \& Noller, P. (1990). Attachment style as a predictor of adult romantic relationships.Journal of Personality and Social Psychology, 58(2), 281-291.

Fraley, R. C. (2019). Attachment in adulthood: Recent developments, emerging debates, and future directions. Annual Review of Psychology, 70, 401-422. https://doi.org/10.1146/annurev-psych-010418$\underline{102813}$

Fraley, R. C., Vicary, A. M., Brumbaugh, C. C., \& Roisman, G. I. (2011). Patterns of stability in adult attachment: An empirical test of two models of continuity and change. Journal of Personality and Social Psychology, 101(5), 974-992. https://doi.org/10.1037/a0024150

Gillath, O., Mikulincer, M., Birnbaum, G. E., \& Shaver, P. R. (2008). When sex primes love: Subliminal sexual priming motivates relational goal pursuit. Personality and Social Psychology Bulletin, 34, 1057-1069.

Haffner, D. W. (1998). Facing facts: Sexual health for American adolescents. Journal of Adolescent Health, 22, 453-459.

Hazan, C., \& Shaver, P. R. (1987). Romantic love conceptualized as an attachment process. Journal of Personality and Social Psychology, 52, 511-524. 
Hazan, C., \& Zeifman, D. (1994). Sex and the psychological tether. In K. Bartholomew \& D. Perlman (Eds.), Advances in Personal Relationships: Vol. 5. Attachment processes in adulthood (pp. 151-177). London, UK: Jessica Kingsley.

Hogarth, H. \& Ingham, R. (2009). Masturbation among young women and associations with sexual health: An exploratory study. Journal of Sex Research, 46, 558-567.

Horne, S., \& Zimmer-Gembeck, M. J. (2005). Female sexual subjectivity and well-being: Comparing late adolescents with different sexual experiences. Sexuality Research \& Social Policy, 2,25-30.

Hyde, J. S., \& Jaffee, S. R. (2000). Becoming a heterosexual adult: The experiences of young women. Journal of Social Issues, 56, 283-296.

Impett, E. A., Muise, A., \& Harasymchuk, C. (2018). Giving in the bedroom: The costs and benefits of responding to a partner's sexual needs in daily life. Journal of Social and Personal Relationships. https://doi.org/10.1177/0265407518787349

Knee, C. R., Hadden, B. W., Porter, B., \& Rodriguez, L. M. (2013). Self-determination theory and romantic relationship processes. Personality and Social Psychology Review, 17(4), 307-324.

Lehmiller, J. J. (2018). Tell me what you want: The science of sexual desire and how it can help you improve your sex life. Robinson Publishing.

Lemay Jr., E. P., \& Spongberg, K. (2015). Perceiving and wanting to be valued by others: implications for cognition, motivation, and behavior in romantic relationships. Journal of Personality, 83, 464-478.

Li, T. and Chan, D. K. (2012), How anxious and avoidant attachment affect romantic relationship quality differently: A meta-analytic review. Eur. J. Soc. Psychol., 42: 406-419. doi:10.1002/ejsp.1842

Kashdan, T. B., Adams, L. M., Farmer, A. S., Ferssizidis, P., McKnight, P. E., \& Nezlek, J.B. (2014). Sexual healing: daily diary investigation of the benefits of intimate and pleasurable sexual activity in socially anxious adults. Archives of Sexual Behavior, 43, 1417-1429.

Kashdan, T. B., Goodman, F. R., Stiksma, M., Milius, C. R., \& McKnight, P. E. (2018). Sexuality leads to boosts in mood and meaning in life with no evidence for the reverse direction: a daily diary investigation. Emotion, 18, 563-576.

Koleva, S., Selterman, D., Iyer, R., Ditto, P., \& Graham, J. (2014). The moral compass of insecurity: Anxious and avoidant attachment predict moral judgment. Social Psychological and Personality Science, 5(2), 185-194.

Mattingly, B. A., McIntyre, K. P., \& Selterman, D. (2018). Individual differences and romantic relationships: Bidirectional influences on self and relational processes. In V. Zeigler-Hill \& T. Shackelford (Eds.), The SAGE handbook of personality and individual differences. London, UK: SAGE. 
Mikulincer, M., Shaver, P. R., Sapir-Lavid, Y., \& Avihou-Kanza, N. (2009). What's inside the minds of securely and insecurely attached people? The secure-base script and its associations with attachmentstyle dimensions. Journal of Personality and Social Psychology, 97, 615-633.

Mitchell, S. A. (1988). Sex without drive (theory). In S. A. Mitchell (Ed.), Relational Concepts in Psychoanalysis. Cambridge, MA: Harvard University Press.

Mohr, J. J., \& Fassinger, R. E. (2003). Self-acceptance and self-disclosure of sexual orientation in lesbian, gay, and bisexual adults: An attachment perspective. Journal of Counseling Psychology, 50, 482-495.

Moore, S., \& Rosenthal, D. A. (1993). Sexuality in adolescence. New York: Routledge.

Moors, A. C., Conley, T. D., Edelstein, R. S., \& Chopik, W. J. (2015). Attached to monogamy? Avoidance predicts willingness to engage (but not actual engagement) in consensual non-monogamy. Journal of Social and Personal Relationships, 32(2), 222-240.

Moors, A. C., Matsick, J., \& Schechinger, H. (2017). Unique and shared relationship benefits of consensually non-monogamous and monogamous relationships: A review and insights for moving forward. European Psychologist, 22(1), 55-71.

Moors, A. C., Matsick, J. L., Ziegler, A., Rubin, J., \& Conley, T. D. (2013). Stigma toward individuals engaged in consensual non-monogamy: Robust and worthy of additional research. Analyses of Social Issues and Public Policy, 13(1), 52-69.

Muise, A., \& Impett, E. A. (2015). Good, Giving, and Game: The Relationship Benefits of Communal Sexual Motivation. Social Psychological and Personality Science, 6(2), 164-172.

Muise, A., Impett, E. A., Kogan, A., \& Desmarais, S. (2013). Keeping the Spark Alive: Being Motivated to Meet a Partner's Sexual Needs Sustains Sexual Desire in Long-Term Romantic Relationships. Social Psychological and Personality Science, 4, 267-273.

Penke, L., \& Asendorpf, J. B. (2008). Beyond global sociosexual orientations: A more differentiated look at sociosexuality and its effects on courtship and romantic relationships. Journal of Personality and Social Psychology, 95(5), 1113-1135.

Pistole, M. C. (1989). Attachment in adult romantic relationships: Style of conflict resolution and relationship satisfaction. Journal of Social and Personal Relationships, 6(4), 505-510.

Pistole, M., Clark, E. M., \& Tubbs, A. L. (1995). Love relationships: Attachment style and the investment model. Journal of Mental Health Counseling, 17, 199-209.

Potard, C., Courtois, R., Reveillere, C., Brechon, G., \& Courtois, A. (2017). The relationship between parental attachment and sexuality in early adolescence. International Journal of Adolescence and Youth, 22, 47-56. 
Ritchie, A., \& Barker, M. (2006). 'There aren't words for what we do or how we feel so we have to make them up': Constructing polyamorous languages in a culture of compulsory monogamy. Sexualities, 9(5), 584-601.

Roberts, J. (1994). Surgeon general resigns in masturbation row. British Medical Journal, 309,1604.

Rodrigues, D., Fasoli, F., Huic, A., \& Lopes, D. (2018). Which partners are more human? Monogamy matters more than sexual orientation for dehumanization in three European countries. Sexuality Research and Social Policy, 15(4), 504-515.

Rubel, A. N., \& Bogaert, A. F. (2015). Consensual nonmonogamy: Psychological well-being and relationship quality correlates. The Journal of Sex Research, 52(9), 961-982.

Sakaluk, J. K., \& Gillath, O. (2016). The causal effects of relational security and insecurity on condom use attitudes and acquisition behavior. Archives of Sexual Behavior, 45, 339-352.

Schachner, D. A., \& Shaver, P. R. (2004). Attachment dimensions and motives for sex. Personal Relationships, 11, 179-195.

Selterman, D., Apetroaia, A., \& Waters, E. (2012). Script-like attachment representations in dreams containing current romantic partners. Attachment \& Human Development, 14, 501-515.

Selterman, D. \& Koleva, S. (2015). Moral judgment of close relationship behaviors. Journal of Social and Personal Relationships, 32(7), 922-945.

Shaver, P. R., Hazan, C., \& Bradshaw, D. (1988). Love as attachment: The integration of three behavioral systems. In R. J. Sternberg \& B. M. L. (Eds.), The Psychology of Love (pp. 68-99). New Haven: CT: Yale University Press.

Simpson, J. A., Rholes, W. S., \& Phillips, D. (1996). Conflict in close relationships: An attachment perspective. Journal of Personality and Social Psychology, 71, 899-914.

Steele, R. D., Waters, T. E. A., Bost, K. K., Vaughn, B. E., Truitt, W., Waters, H. S., Booth-LaForce, C., \& Roisman, G. I. (2014). Caregiving antecedents of secure base script knowledge: A comparative analysis of young adult attachment representations. Developmental Psychology, 50(11), 2526-2538. https://doi.org/10.1037/a0037992.supp

Stefanou, C., \& McCabe, M. P. (2012). Adult attachment and sexual functioning: A review of past research. Journal of Sexual Medicine, 9, 2499-2507.

Stephan, C. W., \& Bachman, G. F. (1999). What's sex got to do with it? Attachment, love schemas, and sexuality. Personal Relationships, 6, 111-123.

Strachman, A., \& Impett, E. A. (2009). Attachment orientations and daily condom use in dating relationships. Journal of Sex Research, 46, 319-329. 
Szielasko, A. L., Symons, D. K., \& Price, E. L. (2013). Development of an attachment-informed measure of sexual behavior in late adolescence. Journal of Adolescence, 36, 361-370.

Tracy, J. L., Shaver, P. R., Albino, A. W., \& Cooper, M. L. (2003). Attachment styles and adolescent sexuality. In P. Florsheim (Ed.), Adolescent romance and sexual behavior: Theory, research, and practical implications (pp. 137-159). Mahwah, NJ: Erlbaum.

Uchino, B. N., Cacioppo, J.T., \& Kiecolt-Glaser, J.K. (1996). The relationship between social support and physiological processes: a review with emphasis on underlying mechanisms and implications for health. Psychological Bulletin, 119, 488-531.

Vicary, A. M., \& Fraley, R. C. (2007). Choose your own adventure: Attachment dynamics in a simulated relationship. Personality and Social Psychology Bulletin,33, 1279-1291. doi:10.1177/0146167207303013

Wade, L., Kremer, E., \& Brown, J. (2005). The incidental orgasm: the presence of clitoral knowledge and the absence of orgasm for women.Women \& Health,42,117-138.

Waters, T. E. A., Bosmans, G., Vandevivere, E., Dujardin, A., \& Waters, H. S. (2015). Secure base representations in middle childhood across two Western cultures: Associations with parental attachment representations and maternal reports of behavior problems. Developmental Psychology, 51(8), 1013-1025. https://doi.org/10.1037/a0039375

Waters, H. S. \& Waters, E. (2006). The attachment working models concept: Among other things, we build script-like representations of secure base experiences. Attachment \& Human Development, 8, 185-197.

Wismeijer, A. A., \& van Assen, M. A. (2013). Psychological characteristics of BDSM practitioners. Journal of Sexual Medicine, 10, 1943-1952.

Yeh, H. C., Lorenz, F. O., Wickrama, K. A., Conger, R. D., \& Elder Jr., G. H. (2006). Relationships among sexual satisfaction, marital quality, and marital instability at midlife.Journal of Family Psychology, 20, 339343.

Zeifman, D., \& Hazan, C. (1997). A process model of adult attachment formation. In S. Duck (Ed.), Handbook of personal relationships: Theory, research and interventions., 2nd ed.(pp. 179-195). Hoboken, NJ: John Wiley \& Sons Inc. 